\title{
Cellulose aerogel particles: control of particle and textural properties in jet cutting process
}

\author{
Baldur Schroeter (1) • Velislava P. Yonkova • Noreen A. M. Niemeyer • \\ Isabella Jung • Imke Preibisch • Pavel Gurikov (1) - Irina Smirnova (D)
}

Received: 7 August 2020/Accepted: 22 October 2020/Published online: 3 November 2020

(C) The Author(s) 2020

\begin{abstract}
Reported approach aims for the synthesis of spherical cellulose beads with high production rates $(0.7-4.1 \mathrm{~kg} / \mathrm{h}$ of hydrogel) via the so-called jet cutting method. To form particles, jets of aqueous cellulose/sodium hydroxide solutions were cut into pieces and collected in a gelation bath (30 wt $\%$ aqueous $\mathrm{H}_{2} \mathrm{SO}_{4}, 20{ }^{\circ} \mathrm{C}$ ). After solvent exchange with ethanol and subsequent supercritical drying, cellulose aerogel particles were obtained. The particles showed high specific surface areas (ca. $400 \mathrm{~m}^{2} / \mathrm{g}$ ) and low bulk (untapped) densities $\left(0.06-0.10 \mathrm{~g} / \mathrm{cm}^{3}\right)$. Variation of
\end{abstract}

Electronic supplementary material The online version of this article (https://doi.org/10.1007/s10570-020-03555-2) contains supplementary material, which is available to authorized users.

B. Schroeter $(\bowtie)$. N. A. M. Niemeyer .

I. Jung · I. Preibisch $\cdot$ I. Smirnova

Institute for Thermal Separation Processes, Hamburg

University of Technology, Eißendorfer Straße 38,

21073 Hamburg, Germany

e-mail: baldur.schroeter@tuhh.de

V. P. Yonkova

Department of Chemical Engineering, University of Chemical Technology and Metallurgy, Kliment Ohridski

Boulevard 8, 1576 Sofia, Bulgaria

P. Gurikov

Laboratory for Development and Modelling of Novel

Nanoporous Materials, Hamburg University of

Technology, Eißendorfer Straße 38, 21073 Hamburg,

Germany cellulose content (4-7 wt $\%$ ) and jet cutting process parameters (cutting frequency, nozzle diameter, jet velocity) turned to be useful parameters for controlling the particles size and shape. Highly spherical particles with sphericity $S P H \geq 0.92$ were obtained in a broad range of achievable particle sizes $(0.4-1.0 \mathrm{~mm})$, with an optimum of $S P H$ at $6 \mathrm{wt} \%$ cellulose content.

Keywords Aerogel $\cdot$ Cellulose $\cdot$ Gelation $\cdot$ Jet cutting $\cdot$ Particles

\section{Introduction}

Aerogels being known as the lightest solid materials have a tremendous potential in a wide range of applications, where high pore volume and high surface area play major roles. Aerogels low densities $(<0.2 \mathrm{~g} /$ $\left.\mathrm{cm}^{3}\right)$, high porosities $(>90 \% \mathrm{v} / \mathrm{v})$, high specific internal surfaces (up to $1200 \mathrm{~m}^{2} / \mathrm{g}$ ) are extraordinary properties, which make them useful materials in many different areas. With the depletion of fossil fuel and increasing environmental concerns, there is an increased need for the use of sustainable and ecofriendly educts, bringing biopolymer based aerogels more in the focus over the last decades (Smirnova and Gurikov 2018). Cellulose based aerogels are promising materials in this context, because they are made from an abundant and cheap source while offering a 
wide range of potential applications e.g. in adsorption, thermal insulation, separation, drug delivery, medical and food sectors and in electro-chemistry after pyrolysis (Fu et al. 2016; Hayase et al. 2014; Deuber et al. 2018; Druel et al. 2018; Mikkonen et al. 2013, 2014; Jack et al. 2017; Cao and Mezzenga 2020; Shen et al. 2015). Despite the wide range of possible applications, the transition from feasibility studies to industrial scale has been realized only in a few cases (Huang 2012). The preparation of aerogels heavily relies on supercritical fluid technology and thus cannot be thought as purely chemical synthesis: it necessarily requires profound engineering knowledge. The overall scheme of biopolymer aerogel production involves three steps: (I) formation of a hydrogel through different mechanisms; (II) solvent exchange; (III) supercritical drying with carbon dioxide at high pressure ( 120 bar) (Ganesan et al. 2018; GarcíaGonzáles et al. 2011). During the gel formation (I) an in situ shaping is possible. This first step significantly determines the physicochemical and mechanical properties of the resulting aerogel. Fast gel formation (i.e. fast reaction kinetics) allows the production of small aerogel particles with well-defined sizes, while slow gel formation is advantageous for the production of homogeneous and larger aerogel structures, e.g. monoliths and slabs. The production of aerogels in particulate form offers advantages such as application in controlled drug release or good sorption performance (García-Gonzáles et al. 2011; Wu and Liu 2017; Krishna Rao et al. 2006). The particles sphericity may have decisive effects on their mechanical stability and applicability, since non-spherical shapes may reduce gel bead strength, leading to cracking in tear shape and non-spherical beads, e.g. resulting in the release of encapsulants (Jin-Wook Woo et al. 2007; Al-Hajry et al. 1999). In addition, high sphericity also improves the aesthetics, which may be desirable for food and pharma applications and is beneficial for controlled mass- and heat transfer, as well as for flowability and compaction (Lee et al. 2013).

Hydrogel particles are classically produced by dripping and spraying methods or emulsion gelation, whereas dripping methods are feasible for the production of particles with diameters $>300 \mu \mathrm{m}$ (Menshutina et al. 2017; Gonçalves et al. 2016; Druel et al. 2020). In the context of aerogel production, particle sizes above $100 \mu \mathrm{m}$ are most suitable for batch supercritical drying as they demonstrate neither agglomeration, nor caking behavior, while the mass transfer can be influenced by the flow rate of $\mathrm{CO}_{2}$ (Selmer et al. 2018, 2019). Furthermore, small aerogel particles can be dried with sc- $\mathrm{CO}_{2}$ with a continuous process, as we recently demonstrated (Mißfeldt et al. 2020).

However, only moderate production rates can be achieved in classical dripping methods or variations thereof. Furthermore, these methods are often limited by high viscosity of the processed polymeric solutions. In the field of high throughput processes, jet cutting of biopolymer solutions has been shown to be a promising and scalable method for production of hydrogel particles with particle diameters in the range from 0.3 up to $1.5 \mathrm{~mm}$ (Preibisch et al. 2018; LópezIglesias et al. 2020). The basic principle of jet cutting is the generation of droplets by splitting a liquid jet into segments with a rotating cutting disc. In first works on the jet cutting process, the influence of some process parameters on size and shape of the resulting hydrogel particles were investigated, but no systematical studies including quantification of influences on particles sphericity were carried out (Preibisch et al. 2018; Prüsse et al. 2000, 2008; Paulo et al. 2017).

The cited publications have in common that alginate was used as material system. Due to its fast gelation, alginate acts as an ideal model system for description and characterization of the jet cutting process, as shown by (Prüsse et al. 2008). Preibisch et al. demonstrated that slower gelation leads to more deformed particles for the same material system (Preibisch et al. 2018). If the results obtained with alginate are compared to the production of cellulose particles via jet cutting, the challenge to determine suitable (and therefore fast) gelation conditions for cellulose solutions arises. Cellulose solutions are generally not easy-gelling agents, with the exception of aqueous cellulose/sodium hydroxide $(\mathrm{NaOH})$ (Budtova 2019). In addition, ionic liquids, which are powerful solvents for cellulose, can be used for dissolution of cellulose and subsequent production of hydrogel beads (Budtova 2019). In order to form a hydrogel from dissolved cellulose, gelation or coagulation has to be initiated, whereas the choice of the right conditions depends on the targeted macroscopic shape and application as well as on the applied cellulose solution. Gelation of cellulose solutions is induced by heat, whilephysical coagulation by phase separationoccurs in cellulose non-solvents like acids 
or ethanol in case of aqueous cellulose $/ \mathrm{NaOH}$ solutions (Budtova 2019; Gericke et al. 2013).

Druel et al. (2018) successfully produced cellulose aerogel beads with specific surface areas in the range from 240 to $300 \mathrm{~m}^{2} / \mathrm{g}$ via jet cutting by dissolving cellulose (2-3 wt\%) in an ionic liquid (5-diazabicyclo[4.3.0]non-5- enium propionate) and coagulate the solutions in different cellulose non-solvents (water, isopropanol, ethanol). In this case, cellulose concentration was identified as the main influence factor for size and shape of the particles, achieving larger particles at higher cellulose concentrations. While the documented work demonstrates principal applicability of the jet cutting process for production of porous cellulose particles, the sphericity of the produced particles was not quantified, and the process parameters of the jet cutting process were not in the focus. Besides a basic, empirical geometrical approach (Eq. 1, Prüsse et al. 2002), no models are documented in literature for prediction of particles size produced by jet cutting,

$d_{\text {particle }}=\sqrt[3]{\frac{3}{2} \cdot d_{\text {nozzle }}^{2} \cdot\left[\frac{v_{\text {jet }}}{f_{\text {cut }}}\right]-d_{\text {wire }}}$

where $d_{\text {particle }}$ is the particle diameter [mm], $d_{\text {nozzle }}$ is the nozzle diameter $[\mathrm{mm}], v_{\text {jet }}$ is the jet velocity $[\mathrm{mm} /$ $\mathrm{s}$ ], $f_{\text {cut }}$ is the cutting frequency $(\mathrm{Hz})$ and $d_{\text {wire }}$ is the diameter of the cutting wire [mm].

Although Eq. 1 includes some process parameters, it is unclear whether it is generally applicable to the production of hydro- and aerogels, since the physicochemical properties of the solutions are not explicitly considered. When it comes to the production of hydroand aerogels, shrinkage during gel formation and later processing steps has also to be taken into account: for example, a volume shrinkage up to $40 \%$ has been documented for gel formation from aqueous cellulose/ $\mathrm{NaOH}$ solutions ( $5 \mathrm{wt} \%$ cellulose content) coagulated in $0.1 \mathrm{~mol} / \mathrm{L}$ acetic acid solutions (Sescousse and Budtova 2009).

This work aims at addressing the above points and determines process conditions for the production of cellulose-based, highly spherical hydro- and aerogel particles with the jet cutting method, using only cheap and biocompatible educts. Our strategy is divided into the following sub-steps: (1) Identification of a green synthesis route for the production of spherical cellulose hydrogel particles; (2) Application of the reaction conditions identified in the step one to the jet cutting process; (3) Quantification and modelling of jet the cutting process and (4) Processing of the jet-cut hydrogels to aerogels. Since for the application of aerogel particles the macroscopic characteristics as well as the microstructure play decisive roles, we aim in our work for a holistic approach, which includes the influence of jet cutting process parameters and biopolymer content on both: particle and textural properties.

\section{Materials and methods}

Materials and experimentation

\section{Preparation of aqueous stock solutions}

A quantity of 20-35 g microcrystalline cellulose type II (JRS Pharma GmbH \& Co. KG, Vivapure ${ }^{\circledR}, 101$ was dispersed in $200 \mathrm{~g}$ demineralized water and left for swelling at $5{ }^{\circ} \mathrm{C}$ for at least for $30 \mathrm{~min} .38 \mathrm{~g}$ of $\mathrm{NaOH}$ (Merck KGaA) were dissolved in 227-242 $\mathrm{g}$ demineralized water and cooled to $-9{ }^{\circ} \mathrm{C}$. The swollen cellulose/water dispersion was added to the $\mathrm{NaOH}$ solution and stirred $(500 \mathrm{rpm})$ at $-9{ }^{\circ} \mathrm{C}$ for two hours in a double jacket glass reactor with a volume of $500 \mathrm{~mL}$ to achieve a homogeneous cellulose solution with a cellulose content of 4-7 wt\% (Table 1).

The solutions were stored at $5{ }^{\circ} \mathrm{C}$ for a maximum of $24 \mathrm{~h}$ and used for further processing.

\section{Preparation of coagulation bath solutions}

Different coagulation bath solutions consisting of diluted (5.0-33 wt \%) aqueous sulfuric acid $\left(\mathrm{H}_{2} \mathrm{SO}_{4}\right.$,

Table 1 Recipes for the preparation of cellulose solutions

\begin{tabular}{lll}
\hline $\begin{array}{l}\text { Cellulose content } \\
{[\mathrm{wt} \%]}\end{array}$ & $\begin{array}{l}\text { Cellulose } \\
{[\mathrm{g}]}\end{array}$ & $\begin{array}{l}\text { Water } \\
{[\mathrm{g}]}\end{array}$ \\
\hline 4.0 & 20.0 & 442 \\
5.0 & 25.0 & 437 \\
6.0 & 30.0 & 432 \\
7.0 & 35.0 & 427 \\
\hline
\end{tabular}

Each solution contains $38 \mathrm{~g} \mathrm{NaOH}$ 
Merck Millipore, Emsure ${ }^{\circledR}$ ), and ethanol $99.9 \%$ (EtOH, Carl Roth GmbH \& Co. KG) were used to induce the coagulation of the cellulose solutions. Temperature of the coagulation bath solutions was varied from 20 to $50{ }^{\circ} \mathrm{C}$.

\section{Hydrogel particle production via dripping method}

Cellulose solutions were extruded from syringes (needle diameter $=0.4 \mathrm{~mm}$ ) into the coagulation bath resulting in an initial droplet volume of $6.88 \mathrm{~mm}^{3}$. Two coagulation baths were employed: with aqueous sulfuric acid and with anhydrous ethanol. The distance between the syringe tip and the coagulation bath was kept small $(3 \mathrm{~cm})$ in order to minimize the impact force originating when droplets hit the surface of the coagulation bath. Precooled cellulose solutions $\left(5{ }^{\circ} \mathrm{C}\right)$ were used in order to avoid thermal gelation of cellulose during the runs before getting in contact with the coagulation bath. During all experiments, the $\mathrm{pH}$ of acidic coagulation baths was controlled before experiments and after extruding 100 hydrogel particles. The $\mathrm{pH}$ change was $\leq 0.1$ in case of coagulation induced by sulfuric acid due to a high excess of the acid compared to the amount of $\mathrm{NaOH}$ introduced with the cellulose solution. Hydrogel particles were collected with a mesh and washed with demineralized water until a $\mathrm{pH}$ value of 2 (for acid induced coagulation) or respectively 9 (EtOH induced coagulation) was reached. Washed particles were transferred to the solvent exchange step.

\section{Hydrogel particle production via jet cutting method}

A jet cutter (geniaLab BioTechnologie GmbH, type S: S1702A) was used for the continuous production of spherical hydrogels. The mode of operation is shown schematically in Fig. 1: precooled cellulose solution $\left(5{ }^{\circ} \mathrm{C}\right)$ was filled into a storage tank and extruded by compressed air through the nozzle (1) passing the rotating cutting disc (2) which cut the liquid jet into small segments.

The initially cylindrical segments form spherical droplets while falling directly into a constantly stirred coagulation bath (3). Based on the results presented in "Determination of coagulation conditions for production of spherical cellulose particles" section, $30 \mathrm{wt} \%$ aqueous $\mathrm{H}_{2} \mathrm{SO}_{4}$ ( $\mathrm{pH}$ 0.1) was used as coagulation solution in jet cutting experiments. Four process

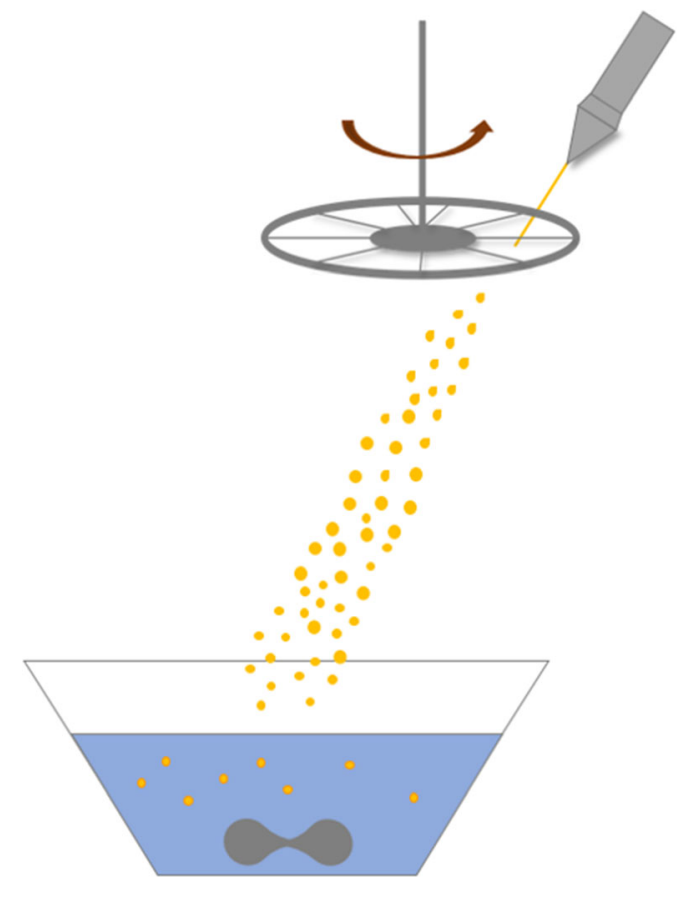

Fig. 1 Scheme of the jet cutting process

parameters were varied in 64 runs: the cutting frequency $\left(f_{\text {cut }}\right)$, the nozzle diameter $\left(d_{\text {nozzle }}\right)$, the jet velocity $\left(v_{\text {jet }}\right)$ and the cellulose content $\left(c_{\text {cell }}\right)$, all other parameters were fixed (see "Materials and Experimentation"Sect. 0). An overview of the varied process parameters is summarized in Table 2, while the settings for the individual experiments are presented in the supplementary information (Online Resource 1, Table S1-S4).

A maximum of $1 \mathrm{~L}$ cellulose solution was processed during each run, corresponding to a maximum change of the $\mathrm{pH}$ value of +0.15 in the coagulation bath. The distance between the nozzle outlet and the surface of the coagulation bath was kept constant at $130 \mathrm{~cm}$. Further constant parameters for all experiments were: the employed cutting disc ( 24 wires with a thickness of $0.15 \mathrm{~mm}$ ), the angle between the nozzle

Table 2 Ranges for variable process parameters of jet cutting experiments

\begin{tabular}{llll}
\hline $\begin{array}{l}c_{\text {cell }} \\
{[\mathrm{wt} \%]}\end{array}$ & $\begin{array}{l}f_{\text {cut }} \\
{[\mathrm{Hz}]}\end{array}$ & $\begin{array}{l}v_{\text {jet }} \\
{[\mathrm{mm} / \mathrm{s}]}\end{array}$ & $\begin{array}{l}d_{\text {nozzle }} \\
{[\mathrm{mm}]}\end{array}$ \\
\hline $4.0-7.0$ & $1200-2400$ & $3200-8600$ & $0.2-0.6$ \\
\hline
\end{tabular}


and cutting disc $\left(10^{\circ}\right)$ and the temperatures of the cellulose solution and the coagulation solution, 5 and $20{ }^{\circ} \mathrm{C}$, respectively. The hydrogel particles were collected in a mesh and washed with demineralized water till a $\mathrm{pH}$ of 2 was reached in the water phase. After washing, the particles were transferred to the solvent exchange.

\section{Solvent exchange}

Solvent exchange was carried out by immersion of the resulting hydrogel particles in $99.9 \mathrm{wt} \%$ ethanol until a minimum final concentration of $98 \mathrm{wt} \%$ ethanol inside the hydrogel particles was reached (controlled by density measurements, Anton Paar, DMA $4500 \mathrm{M})$. Approximately $7 \mathrm{~L} \mathrm{EtOH}$ per liter hydrogel were used.

\section{Supercritical drying}

After the solvent exchange, the particles were sealed into a filter paper bag and placed into a high pressure autoclave with an overall volume of $3.9 \mathrm{~L}$ for supercritical drying with $\mathrm{CO}_{2}$. The supercritical drying was performed at a temperature of $60{ }^{\circ} \mathrm{C}$ and pressure of 120 bar. A continuous flow of $\mathrm{CO}_{2}$ (flow rate $=80-110 \mathrm{~g} / \mathrm{min}$ ) was set through the autoclave until complete extraction of ethanol was achieved after $4 \mathrm{~h}$. The dried particles were collected after slow depressurization (1 bar/min) of the autoclave. Dried particles were stored in sealed tubes ( $25 \mathrm{~mL}$, Sarstedt) in a desiccator prior to analysis.

\section{Specific surface area and pore size distribution}

Low temperature $\mathrm{N}_{2}$ adsorption-desorption analysis was used to investigate microstructural properties of the aerogels (Nova 3000e Surface Area Analyzer, Quantachrome Instruments, Boynton Beach, USA). Single determination was carried out for particles produced via dripping method. Particles produced via jet cutting were measured in triplicate (three measurements of individual batches at each cellulose concentration). An overall sample mass of 20-30 mg was used for each analysis. The specific surface area was determined using the BET (Brunauer-EmmettTeller) method. The pore volume and mean pore diameter were estimated by the BJH (Barrett-Joyner-
Halendia) method. All samples were degassed under vacuum at $60{ }^{\circ} \mathrm{C}$ for $6 \mathrm{~h}$ prior to analysis.

\section{Bulk density}

Bulk (untapped density) of aerogel particles was measured using a graduated cylinder. Dry aerogel particles $(0.3 \mathrm{~g})$ were filled in the cylinder up to a certain volume without tapping. The bulk density was calculated as a ratio of the particles weight and the occupied volume.

\section{Viscosity}

Shear depend viscosity of aqueous cellulose $/ \mathrm{NaOH}$ solutions with a temperature of $5{ }^{\circ} \mathrm{C}$ was determined with a rheometer (Kinexus Pro, Malvern Insturments), covering shear rates in the range $10-10,000 \mathrm{~s}^{-1}$.

\section{Coagulation kinetics and shrinkage during coagulation}

Determination of coagulation kinetics and shrinkage was carried out according to the same protocol as for the dripping method, with the following modifications: only one drop was produced during each run, which was collected in a polystyrene cell (Sarstedt, 10 - $10 \cdot 45 \mathrm{~mm}$ ), filled with $3 \mathrm{~mL}$ of coagulation solution. The cell was placed between a high speed camera (IMAC-CCD S30 video camera module connected to a Leica MZ 125 stereomicroscope) and a light source. The opacity and shape of the droplet during coagulation was monitored with a rate of twenty frames per second. All measurements were carried out in triplicate, evaluation of the results was done by image analysis (Software ImageJ). Shrinkage was determined by evaluation of the maximum particle diameter of the hydrogel droplet $d_{\text {hydro }}$. Coagulation kinetics was evaluated based on the opacity of the droplet, which was represented by grayscale from 0 to 255 , with 255 corresponding as reference (complete transparent droplet). Values of grayscale represented the average along the droplets main axis.

\section{Scanning electron microscope}

The surface properties and the inner structure of the aerogels were characterized via scanning electron 
microscopy (SEM, Zeiss Supra VP55, Jena, Germany). The intact and cut particles were sputtered with a thin layer of gold (Sputter Coater SCD 050, BALTEC) before analysis was started. The measurements were carried out under high vacuum at an accelerating voltage of $2-5 \mathrm{kV}$ and a working distance of $5.8-9.0 \mathrm{~mm}$.

\section{Image analysis of hydrogel and alcogel Particles}

The size and shape of wet gels was determined based on pictures taken by an optical microscope (particles with diameter $<1 \mathrm{~mm}$, VisiScope TL384H, VWR International GmbH Darmstadt, Germany) or camera (Particles with diameter $>1 \mathrm{~mm}$, Canon E0S). 50 particles per experiment were evaluated for determination of the mean particle diameter $d_{\text {mean }}$. Image analysis method (Software ImageJ) was used to determine $d_{\text {mean }}$. In case of irregular shaped particles, the average of the maximum and minimum diameter was used for calculation of $d_{\text {mean }}$.

\section{Image analysis aerogel particles}

Size and shape of dry aerogel particles were determined with a Camsizer XT system (Retsch Technology) in free fall mode. All characterizations were carried out according to DIN 66,141. Particle size $d_{\text {particle }}$ was calculated from the longest feret-diameter and the shortest chord-diameter of each particle projection as follows:

$d_{\text {particle }}=\sqrt{x_{\text {Femax }}^{2}-x_{\text {cmin }}^{2}}$

with $x_{\mathrm{Fe} \text { max }}$ being the longest feret-diameter and $x_{\mathrm{c}}$ min being the shortest chord-diameter of each particle projection. The particle diameter $\mathrm{d}_{\text {particle }}$ of aerogels is given as cumulative distribution [50\% passing, $Q_{3}(50)$ ], based on volume. Particles sphericity $S P H$ is given according to ISO 9276-6 as:

$S P H=\frac{4 \pi A}{P^{2}}$

where $P$ is the measured perimeter/circumference of a particle projection and $A$ is the measured area covered by a particle projection. For an ideal sphere $S P H$ is equal to 1 and for real samples is lower than 1 . The polydispersity of the samples is given as the Span value based on volume:
Span $=\frac{x Q_{3}(90)-x Q_{3}(10)}{x Q_{3}(50)}$

with $x Q_{3}=Q_{3}$ values, where a given particle diameter $x$ is reached, based on volume.

\section{Results and discussion}

Determination of coagulation conditions

for production of spherical cellulose particles

In order to focus on the influence of coagulation conditions on particles properties while excluding the complex process variables introduced by cutting process, a simple syringe dripping method was used for particle production at first. The choice of the material system was motivated by cost- and application aspects: dissolution of aqueous cellulose $/ \mathrm{NaOH}$ solutions was chosen as cheap, bio- and food compatible way for preparation of cellulose stock solutions. It has been shown, that coagulation of cellulose solutions in aqueous $\mathrm{HNO}_{3}$ results in highly spherical aerogel particles with shape supporting skin on the surface (Trygg et al. 2013). In this work we aimed for a similar approach, replacing $\mathrm{HNO}_{3}$ with non-toxic and food grade coagulation media. Two coagulation systems were investigated: acidic coagulation in aqueous solutions of $\mathrm{H}_{2} \mathrm{SO}_{4}$ and coagulation in ethanol (EtOH).

The effects of acid content $c_{\mathrm{H} 2 \mathrm{SO} 4}(5-33 \mathrm{wt} \%)$ and temperature of the coagulation solution $T_{\text {gel }}(20$ and $50{ }^{\circ} \mathrm{C}$ ) were investigated. Different shapes of cellulose hydrogels were obtained in dependence of the acids content and choice of coagulation solution (Fig. 2).

Particles coagulated in EtOH showed flat and flakelike appearance with mean diameter larger than the thickness. Acid induced coagulation lead by contrast to hollow, donut like structures with mean diameter larger than the thickness at the lowest acid concentration (5 wt\%). Particles for which the thickness was comparable to the mean diameter were obtained at $c_{\mathrm{H} 2 \mathrm{SO} 4} \geq 15 \mathrm{wt} \%$, whereas slightly elongated species were produced at $c_{\mathrm{H} 2 \mathrm{SO} 4}=15-20 \mathrm{wt} \%$ and highly spherical hydrogel particles at $c_{\mathrm{H} 2 \mathrm{SO} 4} \geq 25 \mathrm{wt} \%$. The mean particle diameter $d_{\text {mean }}$ was not affected by the coagulation baths temperature and acid concentration (average $d_{\text {mean }}=2.36 \pm 0.02 \mathrm{~mm}$ ) (Fig. 3). The results for the acid induced coagulation show that 

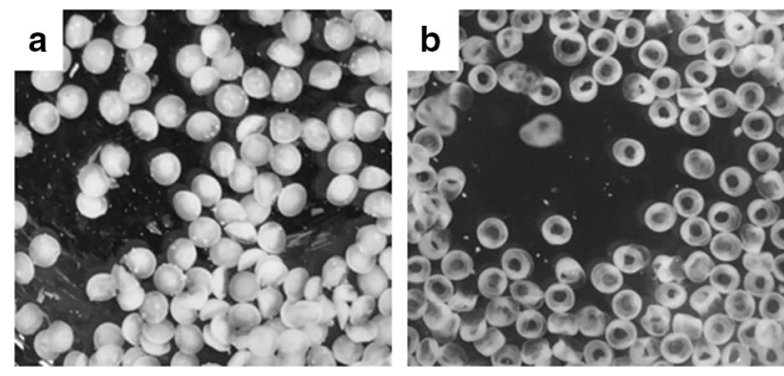

Fig. 2 Cellulose hydrogel particles produced via dripping method under different coagulation conditions: a EtOH, flakes b $c_{\mathrm{H} 2 \mathrm{SO} 4}=5 \mathrm{wt} \%$, hollow structures

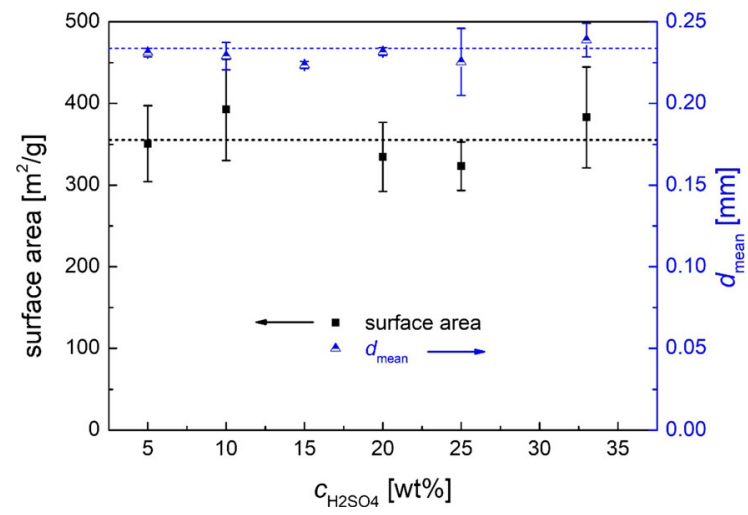

Fig. 3 Mean diameter of hydrogels and BET surface area of aerogels in dependence of $c_{\mathrm{H} 2 \mathrm{SO} 4}$ in dripping method. All values are given as the average of the experiments at $T_{\mathrm{Gel}}=20{ }^{\circ} \mathrm{C}$ and $50{ }^{\circ} \mathrm{C}$, the error bars corresponding to the standard deviation of the averaged. Dashed lines represent the average of all values

acid concentration has a significant influence on macroscopic shape, indicating that droplets are faster stabilized at higher acid concentrations. The phase separation processes for coagulation in EtOH seemed not to be fast enough, leading to strong deformation of the droplet.

As changes of macroscopic shape are also documented in comparable works of, their results are discussed in relation to our work in the following (Trygg et al. 2013; Sescousse et al. 2011). In the latter publication, pure water was used as coagulation medium and the changes of particles shape could be attributed to different process parameters such falling length $(0.5-10 \mathrm{~cm})$ of the droplet and water temperature $\left(20-40{ }^{\circ} \mathrm{C}\right)$. Spherical particles were obtained at higher coagulation bath temperatures $\left(40^{\circ} \mathrm{C}\right)$ and with cellulose solutions which were thermally pre-gelled for $60 \mathrm{~min}$. The pre-gelation step changes the
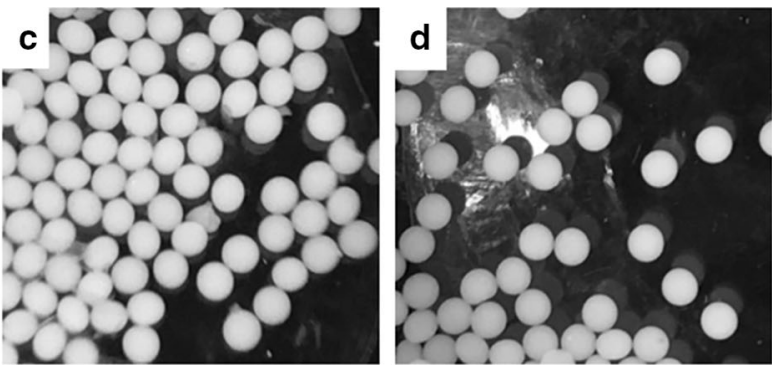

c $c_{\mathrm{H} 2 \mathrm{SO} 4}=15 \mathrm{wt} \%$, elongated and round particles d $c_{\mathrm{H} 2 \mathrm{SO} 4-}$ $=33 \mathrm{wt} \%$, highly spherical particles. All pictures are from experiments carried out at $T_{\text {gel }}=20^{\circ} \mathrm{C}$

viscosity of the cellulose solution and has a beneficial effect on the stabilization of droplets and maximization of coagulation rate. From the process optimization point of view the pre-gelling can be considered as an undesired extra-step. Furthermore, an increased viscosity of the pre-gelled solution may cause nozzle blockage (Preibisch et al. 2018). In this work, no pregalation took place, thus, the changes of the macroscopic shape can only be attributed to the changes of $c_{\mathrm{H} 2 \mathrm{SO} 4}$ without any need of pre-gelation and higher temperatures for the production of round particles. While the BET surface area of aerogels was $115 \pm 6.5 \mathrm{~m}^{2} / \mathrm{g}$ for gels coagulated in $\mathrm{EtOH}$, higher surface areas were obtained by acidic coagulation, with no specific trend in dependence of acids concentration and temperature (average $=357 \pm 30 \mathrm{~m}^{2} / \mathrm{g}$ ) (Fig. 3). Achieved surface areas are in the general higher range and are in good agreement with values reported for cellulose II aerogels coagulated from $\mathrm{NaOH} /$ urea/ $\mathrm{H}_{2} \mathrm{O}, \mathrm{LiOH} / \mathrm{urea} / \mathrm{H}_{2} \mathrm{O}$ (Budtova 2019).

Examination of SEM pictures of cellulose aerogels revealed, that the macroscopic shape adopted at the coagulation step was retained during solvent exchange and supercritical drying (Fig. 4a, b). Particles gelled in presence of $\mathrm{H}_{2} \mathrm{SO}_{4}$ possess a thin skin with a thickness less than $1 \mu \mathrm{m}$, which encloses the inner open porous structure and has a smooth surface (Fig. 4c-e, g-i). The fast formation of a skin may be decisive for the production of round particles, as it can help to fix the particle shape at the beginning of the coagulation process. Even though it was not possible to clearly detect open pores on the skin surface, the results from nitrogen adsorption/desorption analysis prove the permeability (and therefore porosity) of the skin as $\mathrm{N}_{2}$ is able to enter the inner part of the aerogel particles. An open macroporous network is clearly 


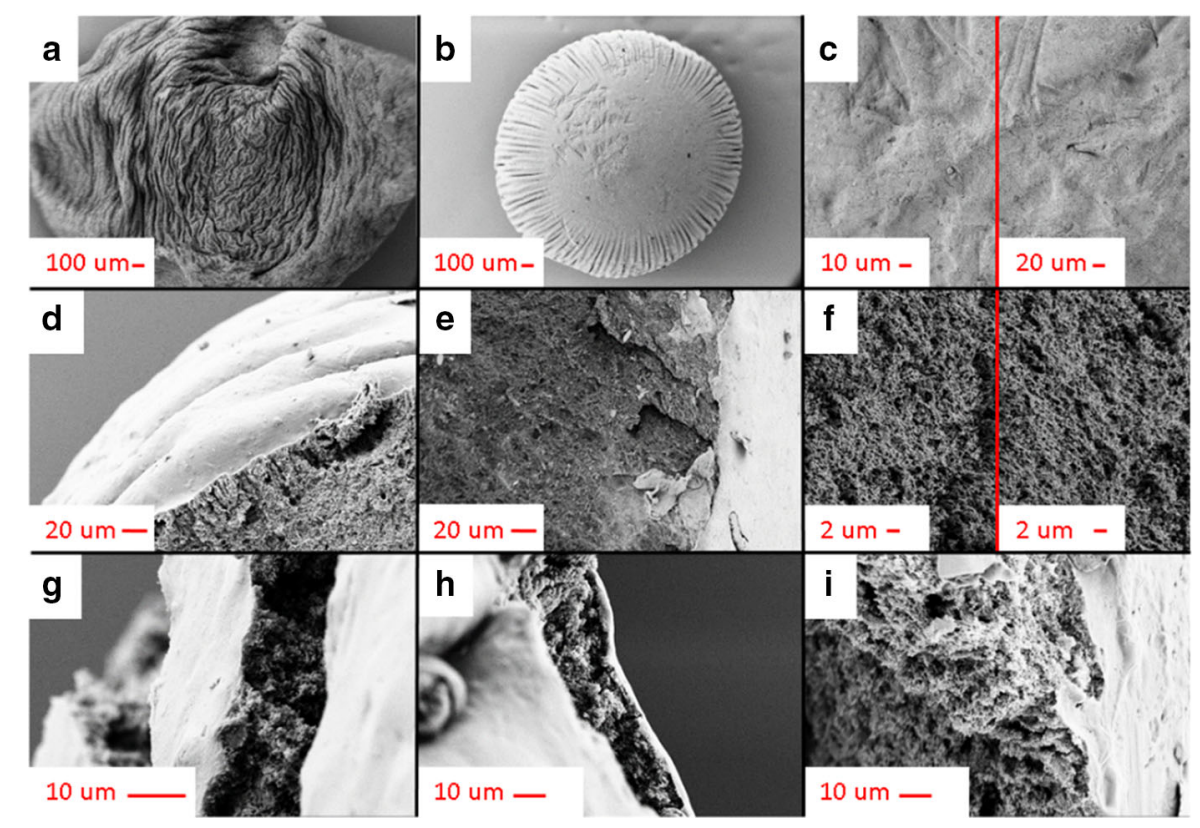

Fig. 4 SEM pictures of cellulose aerogels produced via dripping method. a-f, i $T_{\text {gel }}=20^{\circ} \mathrm{C}, \mathbf{g}, \quad \mathbf{h} T_{\text {gel }}=50^{\circ} \mathrm{C}$ a whole particle, coagulated in ethanol b whole particle, coagulated in acid $c_{\mathrm{H} 2 \mathrm{SO} 4}=33 \mathrm{wt} \%$ c Surface of particle, $c_{\mathrm{H} 2 \mathrm{SO} 4}=33 \mathrm{wt} \%$ (left) and $c_{\mathrm{H} 2 \mathrm{SO} 4}=5 \mathrm{wt} \%$ (right) $\mathbf{d}$ skin and inner porous structure of particle, $c_{\mathrm{H} 2 \mathrm{SO} 4}=33 \mathrm{wt} \%$ e skin and

seen on SEM pictures, being not significantly affected by acid concentration (Fig. 4f). Since combined results from BET analysis as well as SEM pictures of the inner structure both support the assumption, that variation of $c_{\mathrm{H} 2 \mathrm{SO} 4}$ does not affect the porous network, we can conclude that the acid concentration only influences the skin formation kinetics, and therefore the macroscopic shape of the particles. Once the skin is formed, further coagulation of cellulose (and therefore formation of the inner porous structure) should be diffusion-controlled. Thus, the coagulation rate should mainly depend on the thickness of the skin, but the latter was observed not to be significantly affected under conditions studied (Fig. 4d-e, g-i). Formation of a dense layer below the skin would affect the inner microstructure and would have been detected by $\mathrm{N}_{2}$ porosimetry (Trygg et al. 2013). Therefore, the data suggest that cellulose coagulation in the inner of gel particles occurred homogeneously in acidic solutions under all investigated conditions. Hence, variation of acid content is suitable to control the particles shape, without influencing the microporous structure and properties dependent thereon. inner porous structure of particle, $c_{\mathrm{H} 2 \mathrm{SO} 4}=5 \mathrm{wt} \%$ f inner porous structure of particle, $c_{\mathrm{H} 2 \mathrm{SO} 4}=33 \mathrm{wt} \%$ (left) and $c_{\mathrm{H} 2 \mathrm{SO} 4}=5 \mathrm{wt} \%$ (right), $\mathrm{g}$ skin and inner porous structure of particle, $c_{\mathrm{H} 2 \mathrm{SO} 4}=15 \mathrm{wt} \%$, h skin and inner porous structure of particle, $c_{\mathrm{H} 2 \mathrm{SO} 4}=5 \mathrm{wt} \%$, $\mathbf{i}$ skin and inner porous structure of particle, $c_{\mathrm{H} 2 \mathrm{SO} 4}=15 \mathrm{wt} \%$

Summarizing, we can say that the neutralization with sulfuric acid suggested in this work is a simple, economical and green approach towards spherical cellulose gel particles. However the coagulation mechanisms are not yet fully understood. Since several processes take place at once (e.g. diffusion of $\mathrm{H}_{3} \mathrm{O}^{+}$and $\mathrm{OH}^{-}$, neutralization reactions which may also cause temperature rise, phase separation and coagulation of dissolved cellulose), kinetic studies of coagulation at high acids concentrations are of great importance to get insights into the overall reaction order and time as well as the factors influencing skin formation. This is a part of our ongoing work.

\section{Particle production via jet cutting}

Cellulose hydrogel particles were produced via jet cutting and processed to aerogels particles, which were characterized with respect to the particle diameters $\left(d_{\text {particle }}\right)$, sphericity $(S P H)$ and particle size distribution (quantified as Span). Based on the results, a process window for production of particles with high $S P H$ and narrow particle size distributions (target 
product) could be identified. The given points are discussed in detail in the following.

\section{Particle diameter}

Values of $d_{\text {particle }}$ for aerogels were in the range from 0.4 to $1.0 \mathrm{~mm}$, and highly dependent on $d_{\text {nozzle }}$ while only slightly influenced by $f_{\text {cut }}$ and $v_{\text {jet }}$ in the investigated range of parameters. $v_{\text {jet }}(3.18-8.91 \mathrm{~m} / \mathrm{s})$ was chosen within the boundaries of the process: Too high jet velocities lead to destruction of droplets when hitting the coagulation baths surface, while too low velocities result in high cutting losses or complete deflection of the jet when contacting the cutting disc. Within these limits, production rates of $0.7-4.1 \mathrm{~kg}$ hydrogel per hour could be achieved. The particle size increased linearly with $d_{\text {nozzle, }}$ which is consistent with the predictions from the geometrical model for the jet cutting process (Eq. 1, Fig. 5). Values calculated with Eq. 1 reproduce experimental trends, but are significantly and systematically higher than the experimental
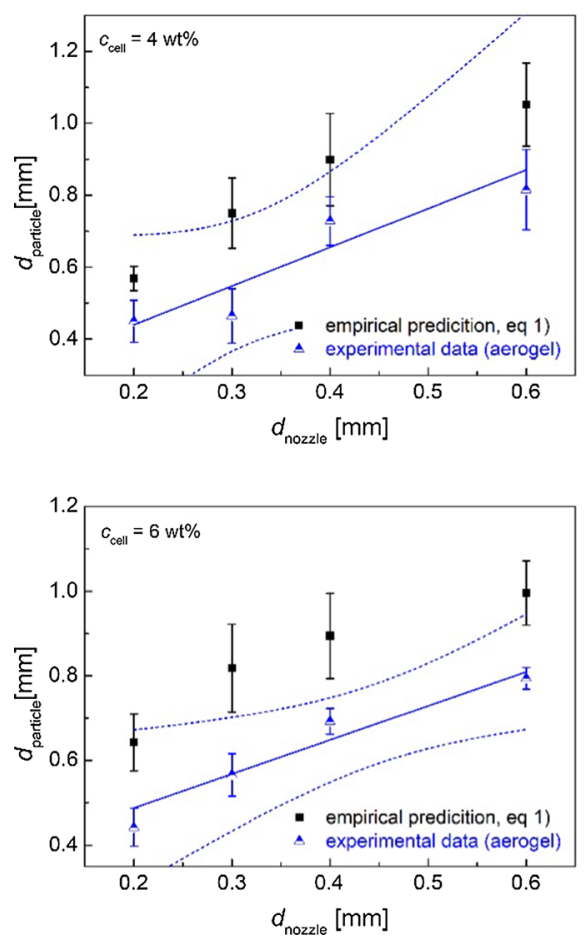

Fig. 5 Dependence of aerogel particles diameter $d_{\text {particle }}$ on the nozzle diameter $d_{\text {nozzle }}$ at different cellulose concentrations in comparison with values predicted with Eq. 1. Each data point represents all settings with a fixed nozzle diameter, but variating results (with an average deviation from experimental results of $38 \%$ ).

This deviation is to be discussed in relation to shrinkage of the particles, which is not taken into account in Eq. 1 and may occur in all steps of cellulose aerogel production: 1. coagulation, 2. solvent exchange, 3. supercritical drying ${ }^{35}$. The degree of shrinkage may vary significantly in dependence of many parameters, e.g. type and concentration of cellulose, dissolution medium, type of non-solvent, solvent exchange strategy, macroscopic shape/size of the material and supercritical drying conditions. Therefore, a direct comparison with the results reported in literature is difficult (Budtova 2019; Sescousse and Budtova 2009; Long et al. 2018; Picher et al. 2014; Schestakow et al. 2016; Heath and Thielemans 2010; Innerlohinger et al. 2006). A high variability of the shrinkage degree during solvent exchange (step 2) is reported for biopolymers in general. As we recently demonstrated analyzing of a large dataset of biopolymer gels, the following empirical exponential relation can be used to quantify
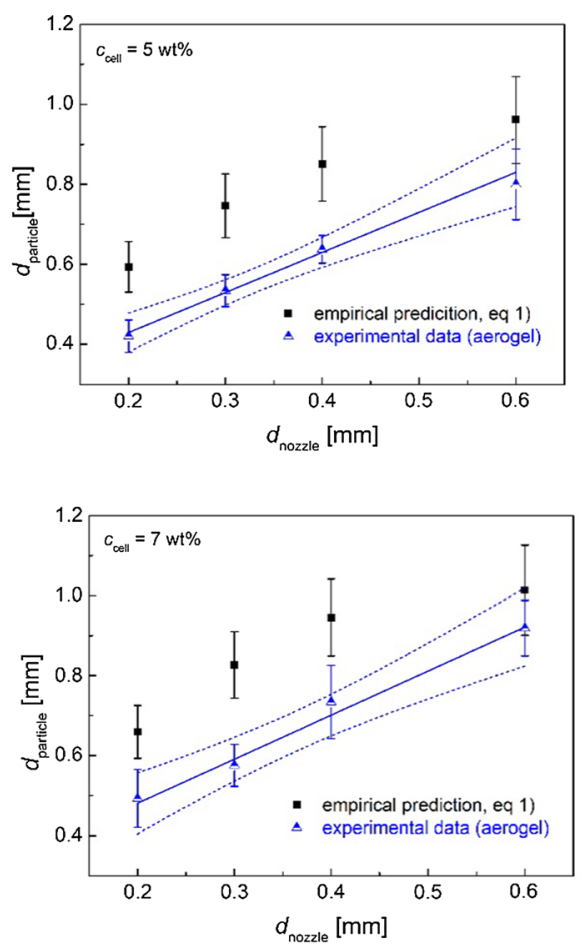

$f_{\text {cut }}$ and $v_{\text {jet }}$ (4 data sets each). The error bars correspond to the standard deviation of the averaged values, straight lines are the linear fits, and dashed lines represent the $95 \%$ confidence interval 
the degree of shrinkage of a hydrogel with the biopolymer concentration $c_{b p}$ (in wt $\%$ ):

$Y=1-0.728 e^{\left(-0.301 c_{b p}\right)}$

with $Y$ is the volumetric yield after the solvent exchange (ratio of the final volume to the initial volume) (Gurikov et al. 2019; Subrahmanyam et al. 2015).

Following Eq. 5, a volumetric shrinkage of approximately $9-22 \%$ (corresponding to 3-8\% linear shrinkage) could be expected during solvent exchange step for the range of $c_{\text {cell }}=4-7 \mathrm{wt} \%$. The experimentally measured total volumetric shrinkage of $\sim 14 \%$ (corresponding to a linear shrinkage of $\sim 5 \%$ ) from hydrogel to aerogel (steps 2 and 3 ) is in the same range compared to these values as well as to the wide range $(6.5-75 \%)$ reported for cellulose-based materials (Budtova 2019; Heath and Thielemans 2010) and was independent of $c_{\text {cell }}$. This result may be attributed to the skin effect, which can provide mechanical stabilization during solvent exchange and supercritical drying, hence protecting the inner porous structure. Since the shrinkage in steps 2 and 3 is not sufficient to explain the differences between calculated (Eq. 1) and the experimental values of $d_{\text {particle, }}$ main shrinkage during the coagulation (step 1), where the gel structure still undergoes dynamic formation and possesses a higher flexibility, should be considered. Shrinkage during coagulation was therefore studied in a separate setup, where size and opacity of single droplets (average initial droplet diameter $d_{O}=3.0 \pm 0.1 \mathrm{~mm}$ ) were monitored by a high speed camera over time (Fig. 6).

After a short contact of $\sim 1 \mathrm{~s}$ with aqueous $\mathrm{H}_{2} \mathrm{SO}_{4}$ solution, transparent (and therefore non-detectable by the camera) droplets became increasingly opaque. Since change of opacity corresponds to the formation of a cellulose 3D-network from dissolved cellulose, the measured changes are indicative for the coagulation progress. Degrees of coagulation and shrinkage were found to be directly related, no further changes were detected after a short reaction time $(<1 \mathrm{~min})$. The coagulation progress followed strictly first order kinetics profile, showing that one factor is dominating the complex coagulation mechanism, which is assumed to be diffusion of $\mathrm{H}_{3} \mathrm{O}^{+}$into the inner part of the particle. Expressed as reaction rate, a first order rate constant $k_{\mathrm{gel}}=(9.2 \pm 0.3) \quad 10^{-2} \mathrm{~s}^{-1}$ for

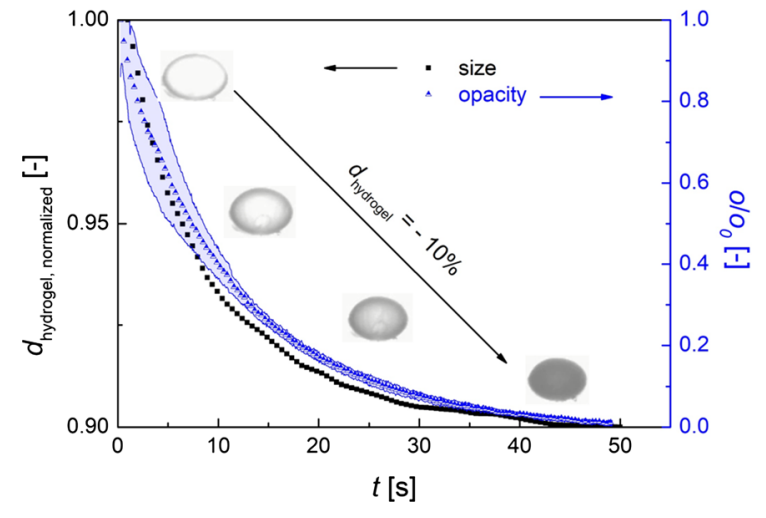

Fig. 6 Changes of size and opacity (normalized) of cellulose $\left(\mathrm{c}_{\text {cell }}=5 \mathrm{wt} \%\right)$ hydrogel droplets over time in $30 \mathrm{wt} \%$ aqueous $\mathrm{H}_{2} \mathrm{SO}_{4}$ at $T_{\text {gel }}=20^{\circ} \mathrm{C}$, averaged values of triple determinations. The error corresponds to the standard deviation. $O / O_{0}$ is the opacity at time $t$ relative to the initial opacity, $d_{\text {hydrogel }}$ corresponds to the maximum particle diameter at time $t$

coagulation can be calculated from linear fitting $\left(\mathrm{R}^{2}>0.991\right)$ of $\ln o / o_{0}$ vs $t$. Taking into account the overall linear shrinkage during the hydrogel formation $(10 \%)$ and additional linear shrinkage during further processing $(5 \%)$, Eq. 1. can simply be supplemented by a shrinkage factor $s$ [\%] (equivalent to the total linear shrinkage), which increases the average accuracy of the predicted particle diameter by $21-83 \%$ :

$\frac{d_{\text {particle }}}{s}=\sqrt[3]{\frac{3}{2} \cdot d_{\text {nozzle }}^{2} \cdot\left[\frac{v_{\text {jet }}}{f_{\text {cut }}}\right]-d_{\text {wire }}}$

Remaining deviations may be explained by following factors: (1) small fraction of the solution in the jet cutting forms smaller particles (so called cutting and spray losses) which eventually also fall into the coagulation bath; (2) initial shrinkage in the first second of the reaction right after contact of the droplet with the coagulation medium (which was not taken into account). Thus, Eq. 1 and refined Eq. 6 are generally suitable for the description of cellulose aerogel particles production via jet cutting and allows an approximate estimation of the final aerogel particle size as a function of jet cutting parameters. A more precise, but purely empirical interpolative prediction for this system is provided by statistical modelling which was made based on our experimental results (Eq. 7): 


$$
\begin{aligned}
d_{\text {particle }}= & 2.5 \cdot 10^{-2}+1.4 \cdot d_{\text {nozzle }}-7.0 \cdot 10^{-5} \cdot f_{\text {cut }} \\
& +3.6 \cdot 10^{-2} \cdot v_{\text {jet }}
\end{aligned}
$$

This simple linear process model proved to be sufficient for a highly accurate (average accuracy of $\left.93 \%, R_{\text {model }}^{2}=0.90\right)$ description. The statistical relevance of the model terms was verified by analysis of variances (ANOVA), documenting adequate precision and signal-to-noise ratio as well as the significance of the individual influence factors (Online Resource 1, Table S5-S6). In accordance with the experimental results, all jet cutting parameters were significant with the largest influence of $d_{\text {nozzle }}$ on $d_{\text {particle. Since }} c_{\text {cell }}$ was a non-significant term, cellulose concentration is not included in the model Eq. 7.

\section{Sphericity}

Despite the relevance for many applications, no systematic quantitative descriptions of the influences of jet cutting process parameters on $\mathrm{SPH}$ of hydro- and aerogels have so far been published, to the best of authors' knowledge. Qualitative descriptions can be found in the works of Preibisch et al. (2018). and Prüsse et al. (2000, 2002 and 2008), quantitative $S P H$ values in the range of $0.71-0.92$ have been given by López-Iglesias et al. (2020) for some selected jet cutting parameters. Thus, the goal of this work is to produce highly spherical aerogel particles and to establish quantitative relations between the sphericity and jet cutter settings and $c_{\text {cell }}$.

A rough categorization of particles quality in terms of $S P H$ is carried out by definition of three particle categories (Fig. 7): $S P H<0.88$ "poor" (particle irregularly shaped surface, partially deformed), $S P H=$ 0.88-0.91 "medium" (slightly deformed surface, partially elongated particles) and $S P H \geq 0.92$ "good" (intact surface, from slightly elongated to perfectly round particles). $S P H$ correlates linearly $\left(\mathrm{R}^{2}=0.999\right)$ with cellulose concentration in the range $c_{\text {cell }}=4$ 6 wt\% (Fig. 8, Eq. 8):

$$
S P H=(0.767 \pm 0.004)+(2.95 \pm 0.07) \cdot 10^{-2} \cdot c_{\text {cell }}
$$

Increasing $c_{\text {cell }}$ leads to a higher viscosity of aqueous cellulose $/ \mathrm{NaOH}$ solutions, which has a beneficial effect on formation of round hydrogel beads in dripping processes, since elastic properties are dominating over viscous ones, helping the droplets to resist impact forces when hitting the coagulation baths surface (Sescousse et al. 2011).

It is notable that with decreasing $c_{\text {cell }}$ jet cutting process parameters gain higher influence as represented by the error bars in Fig. 8. It can be assumed that deformation of the liquid droplets $d e f_{\text {droplet }}$ during the impact on the surface of the coagulation bath is the decisive event for the resulting $S P H$, with high deformations during impact resulting in low sphericities of the products. Therefore this trend can be explained by the relation of the droplet sizes $d_{\text {droplet }}$ and viscoelastic properties of the solutions: According to description of droplet deformation via Ohnesorge number, the deformation of the droplets during impact can be considered being a function of the viscosity of the solutions and the droplet diameter:

$\frac{\sqrt{d_{\text {droplet }}}}{\eta} \rightarrow$ def droplet

With $\eta=$ kinematic viscosity of cellulose solutions [Pa s].

Since $d_{\text {droplet }}$ depends on jet cutting process parameters, higher varieties of deformation during impact and broader ranges of $S P H$ of resulting aerogels particles are obtained at low cellulose concentration with lower viscosities (Fig S1). This is reflected in detail by comparison of $S P H$ with $d_{\text {particle }}$ at different cellulose concentrations (Fig. 9). A
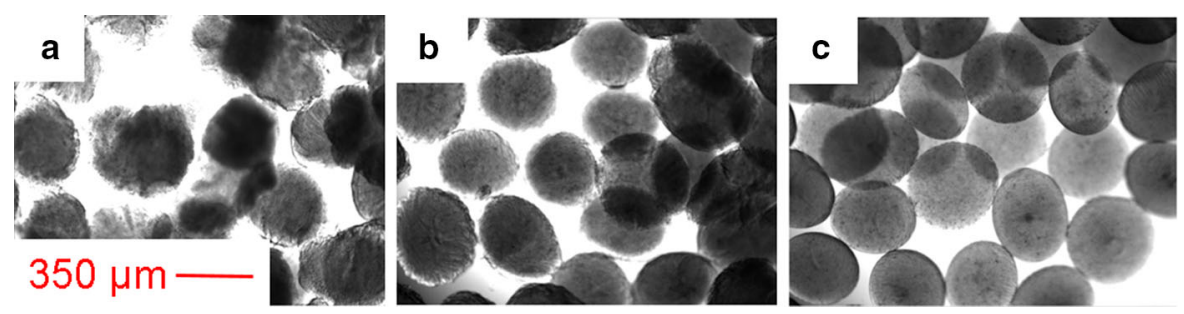

Fig. 7 Pictures of cellulose hydrogels in water. The sphericity $S P H$ values of the corresponding aerogels are: a 0.86 , b 0.92 , c 0.96 


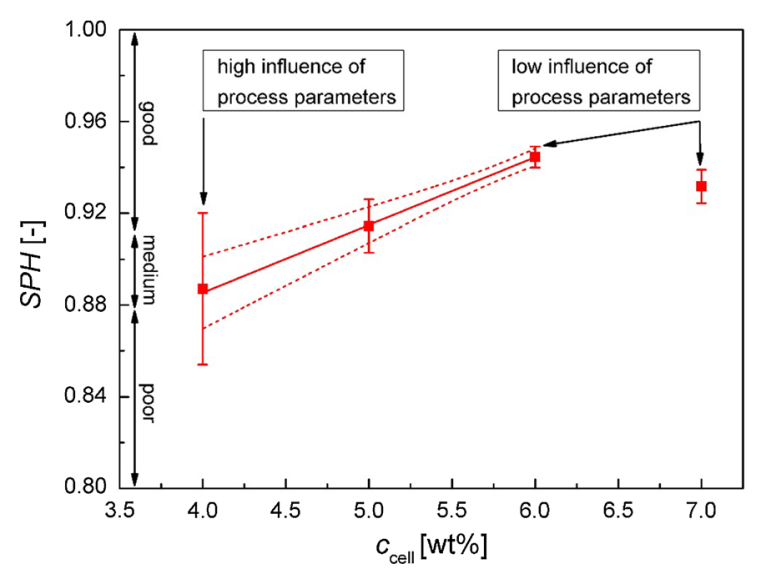

Fig. 8 Sphericity $S P H$ in dependence of cellulose concentration $c_{\text {cel }}$ and corresponding viscosity (see inset). Each data point represents the averaged results from all experiments at the corresponding cellulose concentration with different settings of jet cutting parameters (16 runs each). The errors bars correspond to the standard deviation of the averaged values, therefore representing the influence of jet cutting parameters on $S P H$ at a given $c_{\text {cell. }}$. The straight lines represent linear fitting, and the dashed lines are the $95 \%$ confidence intervals. Double headed arrows represent the ranges of qualitative particle quality

threshold of $d_{\text {particle }}=0.6 \mathrm{~mm}$ can be identified: particles with $d_{\text {particle }} \leq 0.6 \mathrm{~mm}$ have a high and constant sphericity (0.92-0.96): for small particles the viscoelastic properties of the cellulose $/ \mathrm{NaOH}$ solutions are therefore sufficient to allow the droplets to reshape during impact. Above the threshold, $S P H$ decreases drastically at $c_{\text {cell }}=4-5 \mathrm{wt} \%$, while particles with good quality could be obtained up to $d_{\text {particle }}=0.95 \mathrm{~mm}$ at higher cellulose concentrations,

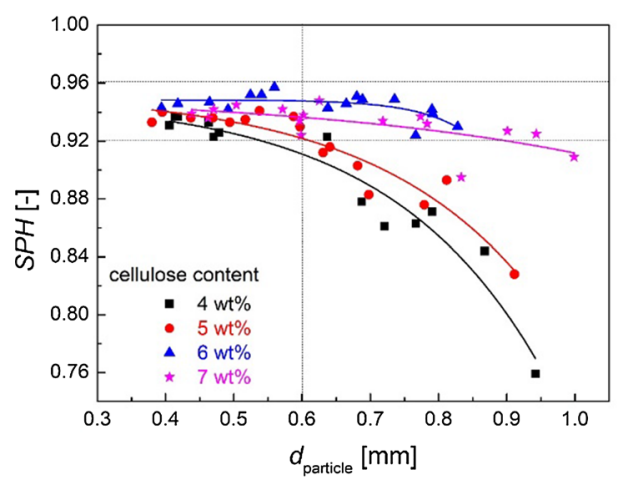

Fig. 9 Sphericity of aerogel particles in dependence of particle diameter at different cellulose concentrations (measured data left, contour plot of $S P H$ predicted by model Eq .10 right). Left: Each point represents an experimental run solid lines are which have sufficient viscosity to withstand increased deformation forces.

In the range of $d_{\text {particle }}<0.6 \mathrm{~mm} \mathrm{SPH}$ increases slightly with increasing cellulose content up to $6 \mathrm{wt} \%$, while further increase to $7 \mathrm{wt} \%$ leads to a slight decrease of SPH (Figs. 8, 9), showing that other effects, e.g. changes of skin formation or coagulation kinetics, counteract the viscoelastic stabilization in this case.

An adequate quantitative description of $S P H$ requires therefore the integration of the complex interactions between $d_{\text {particle }}$ and $c_{\text {cell }}$. This is carried out by statistical evaluation of the individual fits for each cellulose concentration (Fig. 9). A full quadratic description proved applicability of this approach, providing a suitable prediction of $S P H$ in dependence of model terms $\left(R_{\text {model }}^{2}=0.96, p\right.$ values of all terms $<1.0 \cdot 10^{-3}$, variance inflation factors of all terms $<2.3$ ):

$$
\begin{aligned}
\sqrt{S P H}= & 0.75+\left(5.7 \cdot 10^{-1} \cdot d_{\text {particle }}\right) \\
& +\left(4.9 \cdot 10^{-2} \cdot c_{\text {cell }}\right)-\left(6.6 \cdot 10^{-2} \cdot c_{\text {cell }} \cdot d_{\text {particle }}\right) \\
& -\left(6.6 \cdot 10^{-1} \cdot d_{\text {particle }}^{2}\right)-\left(3.0 \cdot 10^{-3} \cdot c_{\text {cell }}^{2}\right) \\
& +\left(8.1 \cdot 10^{-2} \cdot d_{\text {particle }}^{2} \cdot c_{\text {cell }}\right)
\end{aligned}
$$

The corresponding contour plot reflects the interpolated experimental results, with high $\mathrm{SPH}$ at each cellulose concentration for $d_{\text {particle }}<0.6 \mathrm{~mm}$ and higher influence on $S P H$ at $d_{\text {particle }}>0.6 \mathrm{~mm}$ (Fig. 9, right). The plot shows that a maximum of $S P H$ lies at $d_{\text {particle }} \approx 0.5 \mathrm{~mm}$ and $c_{\text {cell }} \approx 6 \mathrm{wt} \%$.

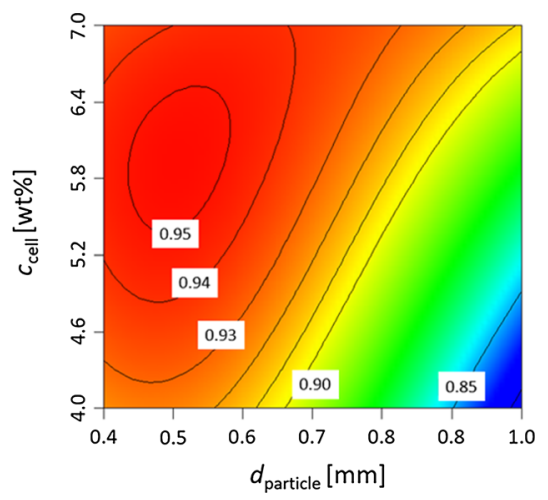

exponential fits. Dotted lines highlight the area of high sphericity (horizontal) and the threshold of $d_{\text {particle }}$ for production of highly sphereous particles at low cellulose concentrations (vertical) 
Particle size distribution

Besides $S P H$, particle size distribution as characterized by Span, is another important characteristics of the particles quality. Span of aerogel particles produced by jet cutting was in the range of $\sim 0.2-0.9$. A large value of span points to a broad and/or multimodal particle size distribution. To our knowledge, there are no strict recommendations what ranges of Span values are attributed to the qualitative terms "monomodal" and "multimodal" size distributions. In this work a categorization is carried out based on the particle size distributions (Online Resource 1, Fig S2S5) and from optical microscopy pictures of corresponding hydrogels. We classified a distribution as "monomodal/narrow" at Span $\leq 0.45$ and "multimodal/broad" distributions at Span $>0.45$ (Fig. 10, left). It is to note that such categorization may significantly depend on the evaluated system: for instance, Chebil et al. (2018) defined a monomodal distribution for Span values less than 1.2. We observed that Span values are highly related to SPH (Fig. 10, right), which is rooted in the evaluation method: because size and shape is evaluated based on the projected area, different orientation, for instance, slightly elongated or flattened species, leads to broadening of detected distributions.

Narrow distributions are observed at $\mathrm{SPH}>0.92$. Some relatively high Span values at $\mathrm{c}_{\text {cell }}=7 \mathrm{wt} \%$ at $S P H=0.90-0.94$ can be explained by the entrapment of air bubbles inside the particles at these conditions. From a practical standpoint, our results show that narrow and monomodal size distributions are achievable via jet cutting at all cellulose concentrations studied in this work.
Jet cutting process

Based on all presented results, a process window of jet cutting parameters can be suggested for the production of particles with high sphericity (Online Resource 1, Table S9). Besides the product properties, issues regarding the process such as bubble formation and nozzle blockage are also taken into account.

Blockage or runaway of the jets angle occurred sometimes at higher cellulose content (6-7 wt\%) and for nozzles with small diameter $(200-300 \mu \mathrm{m})$. Since aqueous $\mathrm{NaOH} /$ cellulose solutions are gelling over time (also in the feeding vessel of the jet cutting device) and the gel point depends on $c_{\text {cell }}$ and temperature, thermal gelation of cellulose solution leftovers near the nozzle outlet may result in partial or full blockage of the liquid jet (Gavillon and Budtova 2008; Cedric Roy and Budtova 2003). It is important to note that the process window could be enlarged by: (1) feeding from a cooled chamber to minimize the gelation of the stock solution; (2) degassing of the coagulation solution in order to exclude bubble entrapment effects in large particles at high cellulose content.

At the current state, an optimum for particles with maximized $S P H$, narrow particle size distribution and good processability can be identified in the range of $d_{\text {particle }} \approx 500-600 \mu \mathrm{m}$ at $c_{\text {cell }}=6 \mathrm{wt} \%$, working with a nozzle diameter of $400 \mu \mathrm{m}$.

Influence of cellulose content on porous structure

Cellulose aerogels from the jet cutting process were analyzed for textural properties after drying and the relations of jet cutting process parameters and cellulose content were determined. Textural properties were only dependent on cellulose content and not
Fig. 10 Exemplary particle size distributions (left), Span in dependence of SPH and $c_{\text {cell }}$ (right). The solid line corresponds to global fitting of all data points with a power function, the dashed lines to the $95 \%$ confidence interval
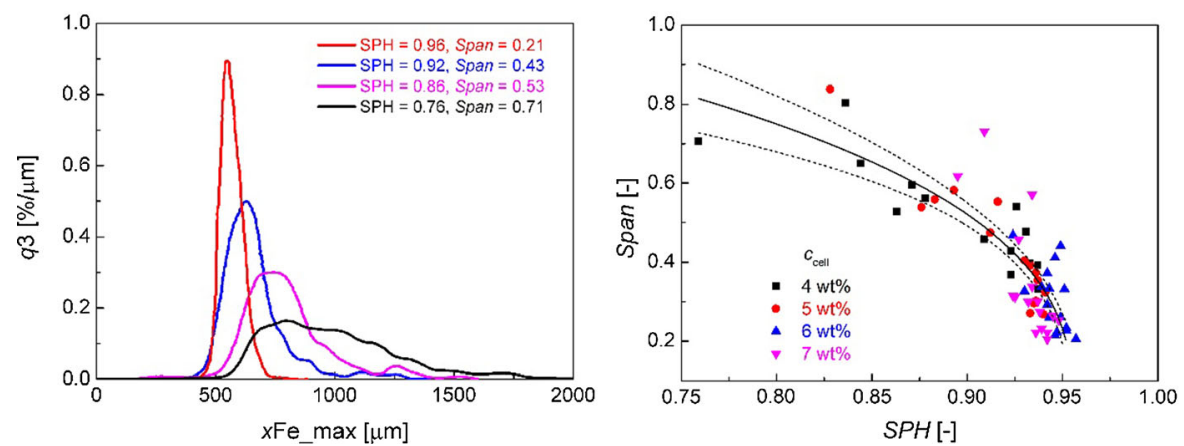
related to particle size and sphericity. Interestingly, cellulose content had no specific effect on the BET specific surface area. The latter was found to be on average equal to $376 \pm 37 \mathrm{~m}^{2} / \mathrm{g}$ (Fig. 11). As we discussed above, a $\sim 10 \%$ decrease in the droplet diameter during coagulation was observed. A further $\sim 5 \%$ linear decrease in the droplet diameter was observed during the solvent exchange and drying processes (Fig. 11).

These size reductions translate into a linear decrease of $(1-0.10) \cdot(1-0.05)=0.855$ for the entire transformation from cellulose solution to the final aerogel. This linear decrease corresponds to the total volumetric change of $0.855^{3}=0.625$, i.e. around $63 \%$ volume of the cellulose solution is preserved in the gelation, solvent exchange and supercritical drying steps. The volume reduction allows a simple estimation of the envelope densities of the resulting aerogels, as they are difficult to measure experimentally (Gurikov et al. 2019, see supporting information for details). The envelope densities $\rho_{e}\left(c_{\text {cell }}\right)$ can be estimated to be $0.07,0.09,0.11$ and $0.13 \mathrm{~g} / \mathrm{cm}^{3}$ for $4,5,6$ and $7 \mathrm{wt} \%$ cellulose solutions, respectively.

The shape of pores in cellulose aerogels is still under discussion, and has been reported to be noncylindrical, e.g. net-like aerogel structures were obtained for gels derived from water $/ \mathrm{NaOH}$ cellulose solutions (Budtova 2019; Rege et al. 2016). Despite of well-known limitations for all types of cellulose aerogels, the average pore width $d_{\text {pore }}\left(c_{\text {cell }}\right)$ can formally be calculated from the cylindrical pores

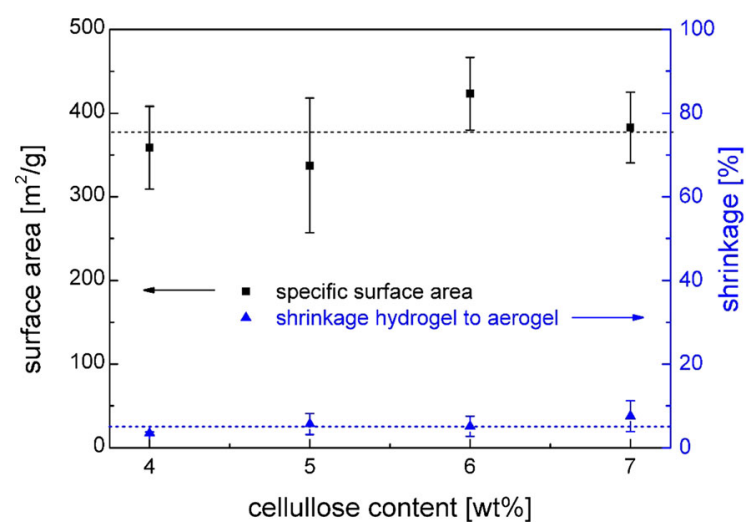

Fig. 11 Linear shrinkage of hydrogel particles and specific surface area of resulting cellulose aerogels particles from the jet cutting process as a function of the cellulose concentration. Dashed lines represent the average values model using the envelope densities $\rho_{e}$ as follows (Rege et al. 2016):

$d_{\text {pore }}\left(c_{\text {cell }}\right)=\frac{4}{S\left(c_{\text {cell }}\right)}\left(\frac{1}{\rho_{e}\left(c_{\text {cell }}\right)}-\frac{1}{\rho_{s}}\right)$

where $S\left(c_{\text {cell }}\right)$ is the specific surface area $\left[\mathrm{m}^{2} / \mathrm{g}\right]$ at the corresponding cellulose concentration, $\rho_{s}$ is the skeletal density of cellulose $\left(1.53 \mathrm{~g} / \mathrm{cm}^{3}\right)$.

Because the specific surface area does not depend on $c_{c e l l}$, the pore width is a reciprocal function of the envelope density. Figure 12a demonstrated this relation for the BJH pore diameters calculated from corresponding pore size distributions (Fig. 12b). A linear relation $\left(R^{2}=0.998\right)$ can indeed be seen between $d_{\text {pore }}$ and $\rho_{e}^{-1}$, with the slope of $1.04 \pm 0.06$. The slope would formally correspond to a value of the surface area ten times larger than what was measured by nitrogen adsorption. This implies that a large contribution to the total pore volume given by the term $1 / \rho_{e}-1 / \rho_{s}$ in Eq. (11) comes from macropores. Similar observations were reported for other biopolymer aerogels (Gurikov et. al 2015), but only seldom articulated in the literature. The BJH pore volume was measured to be constant within experimental errors $\left(3.1-3.8 \mathrm{~g} / \mathrm{cm}^{3}\right)$ across the cellulose concentrations studied. Therefore, the BJH pore volume amounts to $23-45 \%$ of the total pore volume.

Figure 13a demonstrates a linear increase in bulk (untapped) densities with increasing cellulose concentration. It is interesting to compare envelope and bulk densities, because the former are difficult to measure experimentally, whereas the latter is easily accessible: In our case a linear relation was obtained between them $\left(R^{2}=0.94\right)$, (Fig. 13b). As expected for non-monosized particles, the slope of the line is larger than that expected for random packing of hard spheres ( $\sim 0.5-0.6)$. Therefore, when performed in a controlled manner, the bulk density may be used for a rough estimation of the envelope density.

\section{Conclusions}

Highly spherical cellulose aerogel particles were successfully produced via the jet cutting process. Preliminary tests via dripping method showed, that coagulation of aqueous $\mathrm{NaOH} /$ solutions in aqueous solutions of $\mathrm{H}_{2} \mathrm{SO}_{4}$ (ca. $30 \mathrm{wt} \%$ ) led to the formation 

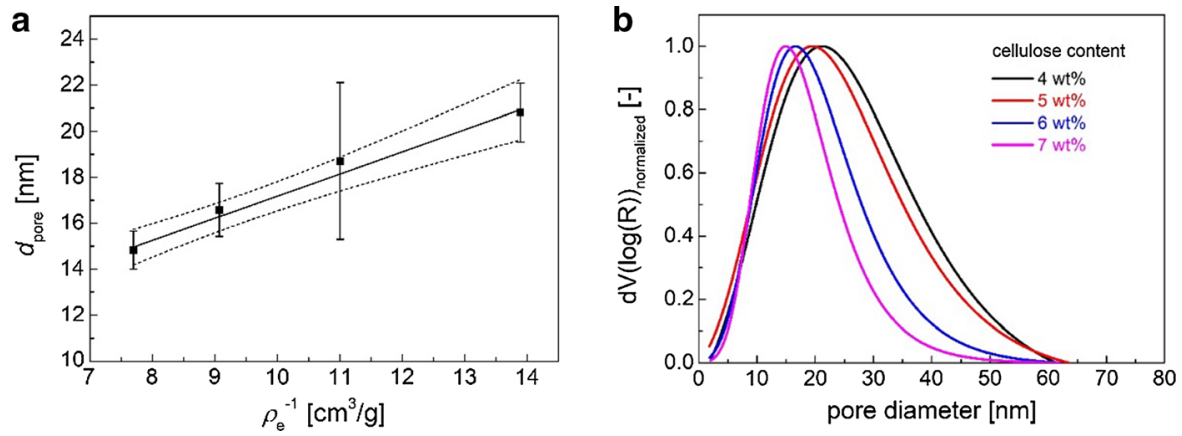

Fig. 12 a Relation between pore diameter and reciprocal envelope density according to the cylindrical pore model, Eq. (10), straight line represents the linear fit, dashed lines the $95 \%$ confidence interval; b experimental BJH pore size distributions
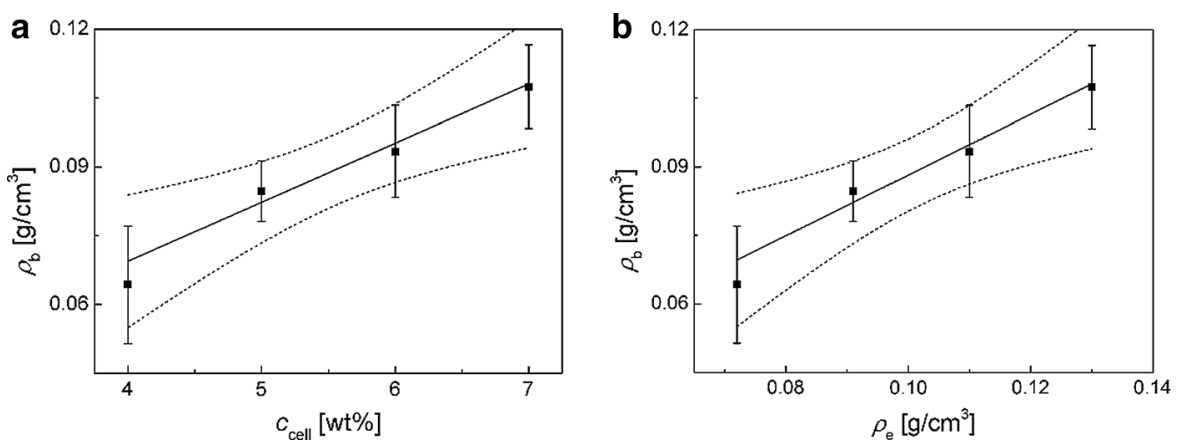

Fig. 13 a bulk density of aerogel particles; b relation between envelope and bulk density. Straight lines represent linear fits, dashed lines the $95 \%$ confidence interval

of round particles, with a thin skin on the particles surface. The influence of the jet cutting process parameters such as jet velocity, nozzle diameter and cutting frequency as well as cellulose content on particle size, shape and particle size distribution was determined, enabling a full quantitative description of the relations between the process parameters. It was found that in the investigated range of parameters the particle size is mainly determined by the nozzle diameter, whereas sphericity is related to the particle diameter and cellulose content. Interpolative models allowed the prediction of macroscopic properties and the identification of optimal process settings for achieving maximum sphericity. The porous structure of cellulose aerogels particles can be controlled by variation of the cellulose content: larger total pore volumes and sizes (for mesopores) were obtained at lower cellulose content. The specific surface area was shown to remain constant at all process conditions. Determination of the shrinkage behavior showed that the coagulation process contributes the most to the overall shrinkage. Shrinkage during the solvent exchange and supercritical drying was demonstrated to be independent of cellulose concentration, which is most likely due to the stabilizing effect of the skin formation. The complex processes during coagulation are still to be understood, in particular the coagulation kinetics and shrinkage during coagulation should have significant impact on micro- and macroscopic properties of the materials, and will be therefore in the focal point of our future works. From the perspective of production on an industrial scale, this work demonstrates a biocompatible and economical way for the production of round cellulose aerogel particles at throughput rates of several $\mathrm{kg}$ hydrogel per hour. The possibility of scale up is given by numbering up: e.g. multi-nozzle approaches allow for simple increase of the production rates, while keeping the influences of jet cutting parameters constant. While the results regarding jet cutting process parameters should be principally transferable to other fast-gelling systems, physicochemical parameters of the reaction system like reaction mechanism and kinetics play also an 
important role for particle shaping and have therefore to be taken into account individually.

Author contributions The manuscript was written through contributions of all authors. All authors have given approval to the final version of the manuscript.

Funding Open Access funding enabled and organized by Projekt DEAL.The authors wish to acknowledge support for this research received from the German Research Foundation (DFG) under the project SM 82/18-1.

\section{Compliance with ethical standards}

Conflict of interest The authors declare that they have no conflict of interest.

Availability of data and material Additional data (Table S1S10, Fig S1-S5) is reported in the electronic supplementary data.

Open Access This article is licensed under a Creative Commons Attribution 4.0 International License, which permits use, sharing, adaptation, distribution and reproduction in any medium or format, as long as you give appropriate credit to the original author(s) and the source, provide a link to the Creative Commons licence, and indicate if changes were made. The images or other third party material in this article are included in the article's Creative Commons licence, unless indicated otherwise in a credit line to the material. If material is not included in the article's Creative Commons licence and your intended use is not permitted by statutory regulation or exceeds the permitted use, you will need to obtain permission directly from the copyright holder. To view a copy of this licence, visit http://creativecommons.org/licenses/by/4.0/.

\section{References}

Al-Hajry HA et al (1999) Electrostatic encapsulation and growth of plant cell cultures in alginate. Biotechnol Prog 15(4):768-774. https://doi.org/10.1021/bp990069e

Budtova T (2019) Cellulose II aerogels: a review. Cellulose 26:8-120. https://doi.org/10.1007/s10570-018-2189-1

Cao Y, Mezzenga R (2020) Design principles of food gels. Nat Food 1:106-118. https://doi.org/10.1038/s43016-0190009-x

Cedric Roy PN, Budtova T (2003) Rheological properties and gelation of aqueous cellulose- $\mathrm{NaOH}$ solutions. Biomacromol 4(2):259-264. https://doi.org/10.1021/ bm020100s

Chebil A, Léonard M, Six JL, Nouvel C, Durand A (2018) Nanoparticulate delivery systems for alkyl gallates: influence of the elaboration process on particle characteristics, drug encapsulation and in-vitro release. Colloids Surf B Biointerfaces 162:351-361. https://doi.org/10.1016/j. colsurfb.2017.11.050
Deuber F, Mousavi S, Federer L, Hofer M, Adlhart C (2018) Exploration of ultralight nanofiber aerogels as particle filters: capacity and efficiency. ACS Appl Mater Interfaces 10(10):9069-9076. https://doi.org/10.1021/acsami.8b004 55

Druel L, Kenkel A, Baudron V, Buwalda S, Budtova T (2020) Cellulose aerogel microparticles via emulsion-coagulation technique. Biomacromol 21(5):1824-1831. https://doi.org/ 10.1021/acs.biomac.9b01725

Druel L, Niemeyer P, Milow B, Budtova T (2018) Rheology of cellulose-[DBNH] $\left[\mathrm{CO}_{2} \mathrm{Et}\right]$ solutions and shaping into aerogel beads. Green Chem 20:3993-4002. https://doi.org/ 10.1039/C8GC01189C

Fu J, He C, Huang J, Chen Z, Wang S (2016) Cellulose nanofibril reinforced silica aerogels: optimization of the preparation process evaluated by a response surface methodology. RSC Adv 6:100326-100333. https://doi.org/ 10.1039/C6RA20986F

Ganesan K et al (2018) Review on the production of polysaccharide aerogel particles. Materials 11(11):2144. https:// doi.org/10.3390/ma11112144

García-González CA, Alnaief M, Smirnova I (2011) Polysaccharide-based aerogels - promising biodegradable carriers for drug delivery systems. Carbohydr Polym 86(4):1425-1438. https://doi.org/10.1016/j.carbpol.2011. 06.066

Gavillon R, Budtova T (2008) Aerocellulose: new highly porous cellulose prepared from cellulose- $\mathrm{NaOH}$ aqueous solutions. Biomacromol 9(1):269-277. https://doi.org/10.1021/ bm700972k

Gericke M, Trygg J, Fardim P (2013) Functional cellulose beads: preparation, characterization, and applications. Chem Rev 113(7):4812-4836. https://doi.org/10.1021/ cr300242j

Gonçalves VSS et al (2016) Alginate-based hybrid aerogel microparticles for mucosal drug delivery. Eur J Pharm Biopharm 107:160-170. https://doi.org/10.1016/j.ejpb. 2016.07.003

Gurikov P, Griffin JS, Steiner SA, Smirnova I (2019) 110th anniversary: solvent exchange in the processing of biopolymer aerogels: current status and open questions. Ind Eng Chem Res 58(40):18590-18600. https://doi.org/10. 1021/acs.iecr.9b02967

Gurikov P, Raman SP, Weinrich D, Fricke M, Smirnova I (2015) A novel approach to alginate aerogels: carbon dioxide induced gelation. RSC Adv 5(11):7812-7818. https://doi. org/10.1039/c4ra14653k

Hayase $\mathrm{H}$ et al (2014) Polymethylsilsesquioxane-cellulose nanofiber biocomposite aerogels with high thermal insulation, bendability, and superhydrophobicity. ACS Appl Mater Interfaces 6(12):9466-9471. https://doi.org/10. 1021/am501822

Heath L, Thielemans W (2010) Cellulose nanowhisker aerogels. Green Chem 12:1448-1453. https://doi.org/10.1039/ C0GC00035C

Huang L (2012) Feasibility study of using silica aerogel as insulation for buildings. Master thesis, KTH school of industrial engineering and management energy technology

Innerlohinger J, Weber HK, Kraft G (2006) Aerocellulose: aerogels and aerogel-like materials made from cellulose. 
Macromol Symp 244:126-135. https://doi.org/10.1002/ masy.200651212

Jack AA et al (2017) The interaction of wood nanocellulose dressings and the wound pathogen P. aeruginosa. Carbohydr Polym 157:1955-1962. https://doi.org/10.1016/j. carbpol.2016.11.080

Jin-Wook Woo SBK, Roh HJ, Park HD, Ji CI, Lee YB (2007) Sphericity optimization of calcium alginate gel beads and the effects of processing conditions on their physical properties. Food Sci Biotechnol 16(5):715-721

Krishna Rao KSV et al (2006) Controlled release of diclofenac sodium and ibuprofen through beads of sodium alginate and hydroxy ethyl cellulose blends. J Appl Polym Sci 102(6):5708-5718. https://doi.org/10.1002/app.25087

Lee BB, Ravindra P, Chan ES (2013) Size and shape of calcium alginate beads produced by extrusion dripping. Chem Eng Technol 36(10):1627-1642. https://doi.org/10.1002/ceat. 201300230

Long LY, Weng YX, Wang YZ (2018) Cellulose aerogels: synthesis, applications, and prospects. Polymers 10(6):623. https://doi.org/10.3390/polym10060623

López-Iglesias C et al (2020) Jet cutting technique for the production of chitosan aerogel microparticles loaded with vancomycin. Polymers 12(2):273. https://doi.org/10.3390/ polym 12020273

Menshutina NV, Lovskaya DD, Lebedev AE, Lebedev EA (2017) Production of sodium alginate-based aerogel particles using supercritical drying in units with different volumes. Russ J Phys Chem B 11:1296-1305. https://doi. org/10.1134/S1990793117080073

Mikkonen KS, Parikka K, Ghafar A, Tenkanen M (2013) Prospects of polysaccharide aerogels as modern advanced food materials. Trends Food Sci Technol 34(2):124-136. https:// doi.org/10.1016/j.tifs.2013.10.003

Mikkonen KS, Parikka K, Suuronen JP, Ghafar A, Serimaa R, Tenkanen M (2014) Enzymatic oxidation as a potential new route to produce polysaccharide aerogels. RSC Adv 4:11884-11892. https://doi.org/10.1039/C3RA47440B

Mißfeldt F, Gurikov LW, Weinrich D, Lied FM, Smirnova I (2020) Continuous supercritical drying of aerogel particles: proof of concept. Ind Eng Chem Res. https://doi.org/10. 1021/acs.iecr.0c01356

Paulo BB, FdeM R, Prata AS (2017) An investigation of operational parameters of jet cutting method on the size of $\mathrm{Ca}-$ alginate beads. J Food Process Eng 40(6):1-8. https://doi. org/10.1111/jfpe. 12591

Pircher N, Veigel S, Aigner N, Nedelec JM, Rosenau T, Liebner F (2014) Reinforcement of bacterial cellulose aerogels with biocompatible polymers. Carbohydr Polym 111:505-513. https://doi.org/10.1016/j.carbpol.2014.04. 029

Preibisch I, Niemeyer P, Yusufoglu Y, Gurikov P, Milow B, Smirnova I (2018) Polysaccharide-based aerogel bead production via jet cutting method. Materials 11(8):1287. https://doi.org/10.3390/ma11081287

Prüsse U et al (2008) Comparison of different technologies for alginate beads production. Chem Pap 62:364-374. https:// doi.org/10.2478/s11696-008-0035-x

Prüsse U, Dalluhn J, Breford J, Vorlop KD (2000) Production of spherical beads by jetcutting. Chem Eng Technol
23(12):1105-1110. https://doi.org/10.1002/1521-4125(20 0012)23:12\%3c1105::AID-CEAT1105\%3e3.0.CO;2-V

Prüsse U, Jahnz U, Wittlich P, Breford J, Vorlop K (2002) Bead production with jetcutting and rotating disk/nozzle technologies. Landbauforsch Völkenrode Sonderh 241:1-10

Rege A, Schestakow M, Karadagli I, Ratke L, Itskov M (2016) Micro-mechanical modelling of cellulose aerogels from molten salt hydrates. Soft Matter 12(34):7079-7088. https://doi.org/10.1039/C6SM01460G

Schestakow M, Karadagli I, Ratke L (2016) Cellulose aerogels prepared from an aqueous zinc chloride salt hydrate melt. Carbohydr Polym 137:642-649. https://doi.org/10.1016/j. carbpol.2015.10.097

Selmer I, Behnecke AS, Farrell P, Bueno A, Gurikov P, Smirnova I (2019) Model development for sc-drying kinetics of aerogels: part 2. packed bed of spherical particles. J Supercrit Fluids 147:149-161. https://doi.org/10.1016/j. supflu.2018.07.006

Selmer I, Behnecke AS, Quiño J, Braeuer AS, Gurikov P, Smirnova I (2018) Model development for sc-drying kinetics of aerogels: part 1. monoliths and single particles. J Supercrit Fluids 140:415-430. https://doi.org/10.1016/j. supflu.2018.07.002

Sescousse R, Budtova T (2009) Influence of processing parameters on regeneration kinetics and morphology of porous cellulose from cellulose- $\mathrm{NaOH}$-water solutions. Cellulose 16:417-426. https://doi.org/10.1007/s10570009-9287-z

Sescousse R, Gavillon R, Budtova T (2011) Wet and dry highly porous cellulose beads from cellulose- $\mathrm{NaOH}$-water solutions: influence of the preparation conditions on beads shape and encapsulation of inorganic particles. J Mater Sci 46:759-765. https://doi.org/10.1007/s10853-010-4809-5

Shen X, Shamshina JL, Berton P, Gurau G, Rogers RD (2015) Hydrogels based on cellulose and chitin: fabrication, properties, and applications. Green Chem 18:53-75. https://doi.org/10.1039/C5GC02396C

Smirnova I, Gurikov P (2018) Aerogel production: current status, research directions, and future opportunities. J Supercrit Fluids 134:228-233. https://doi.org/10.1016/j.supflu. 2017.12.037

Subrahmanyam R, Gurikov P, Dieringer P, Sun M, Smirnova I (2015) On the road to biopolymer aerogels-dealing with the solvent. Gels 1(2):291-313. https://doi.org/10.3390/ gels1020291

Trygg J, Fardim P, Gericke M, Mäkilä E, Salonen J (2013) Physicochemical design of the morphology and ultrastructure of cellulose beads. Carbohydr Polym 93(1):291-299. https://doi.org/10.1016/j.carbpol.2012.03. 085

Wu P, Liu Z (2017) Chitosan aerogel beads with microfibrillated cellulose skeleton for removal of formaldehyde from indoor air. Cellul Chem Technol 51(5-6):521-528

Publisher's Note Springer Nature remains neutral with regard to jurisdictional claims in published maps and institutional affiliations. 